\title{
VOCAÇÃO POLÍTICA DA IGREJA EM TEMPOS SOMBRIOS: DENÚNCIA DE DIETRICH BONHOEFFER AO MESSIANISMO POLÍTICO ${ }^{1}$
}

\section{The political calling of the church in dark times: Dietrich Bonhoeffer's denunciation of political messianism}

\section{Carlos Ribeiro Caldas Filho² Wilhelm Sell ${ }^{3}$}

\begin{abstract}
Resumo:
O artigo apresenta, posto que em síntese, a importância da política na vida social e, ato contínuo, o conceito de messianismo na política. Isto posto, a partir da compreensão de igreja na teologia de Dietrich Bonhoeffer o artigo traz subsídios para uma crítica ao messianismo político atualmente em voga no Brasil, da parte de alguns setores da igreja evangélica. A metodologia empregada foi bibliográfico-documental, usando textos de Bonhoeffer e textos publicados em portais de divulgação, disponíveis em sítios da internet. Quanto à sua estrutura, o artigo apresenta em primeiro lugar a ideia de política e sua importância na vida humana. Ato contínuo, apresenta algumas considerações sobre a ideia de messianismo na política. Seguem-se a apresentação de elementos da teologia de Bonhoeffer que podem fornecer base para uma crítica ao messianismo político e, em conclusão, uma proposta de aplicação destes elementos da teologia bonhoefferiana ao cenário político brasileiro contemporâneo.
\end{abstract}

Palavras-chave: Dietrich Bonhoeffer - Política - Messianismo político - Profetismo.

\section{Abstract:}

This article presents, even in a brief, the importance of politics in social life and, after this, the concept of Messianism in politics. In a second moment, starting from the comprehension of church in the theology of Dietrich Bonhoeffer, the articles provides support for acritique of political Messianism in Brazil that has been practiced nowadays by some sectors of the evangelical church. As its methodology it were used both bibliographical research in Bonhoeffer's texts and texts published in popularization internet sites available in the web as well. Regarding its structure, the articles presents first the ideia of politics and its importance in human life. After this comes a presentation of the idea of Messianism in politics, followed

1 Submetido em: 10.06.2020. Aceito em: 26.08.2020.

2 Graduação em Letras e em Teologia. Mestrado em Teologia pelo Centro Evangélico de Missões e Doutor em Ciências da Religião pela Universidade Metodista de São Paulo. É Pós-Doutor em Teologia pela Faculdade Jesuíta de Filosofia e Teologia de Belo Horizonte, MG. Professor no Programa de Pós-Graduação em Ciências da Religião da PUC, MG. Contato: crcaldas2009@hotmail.com

3 Graduação em Teologia pela Faculdade Luterana de Teologia, SC. Graduando em Filosofia pelo Centro Universitário Claretiano, SP. Mestrado e Doutorado em Teologia pela Faculdades EST, RS. Pastor na Igreja Evangélica de Confissão Luterana no Brasil. Membro do Grupo de Pesquisa Teologia Pública na América Latina da PUC, PR. Contato: wilhelmsell@gmail.com

Protestantismo em Revista | São Leopoldo | v. 46, n. 01 | p. 50-63| Jan./jun. 2020

Disponível em: <http://periodicos.est.edu.br/index.php/nepp> 
by a presentation of some elements of Bonhoeffer's theology that can give a basis for a critique to political Messianism and as a conclusion a proposal of application of these Bonhoefferian theological ideas to contemporary Brazilian political scenario.

Key Words: Dietrich Bonhoeffer - Politics - Political Messianism - Prophetism. Introdução

\section{Introdução}

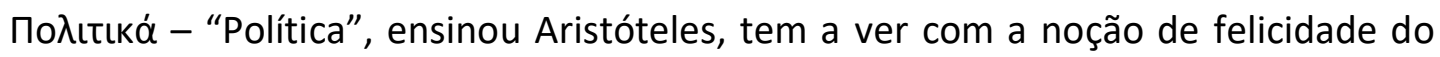
$\alpha v \theta \rho \omega \pi$ ó - anthropos, o humano, que vive na polis. De acordo com o Estagirita, a política se divide em ética, que trata, repetindo, da felicidade do cidadão na polis, e em política propriamente, que tem a ver com a felicidade do grupo, da coletividade. O famoso dito

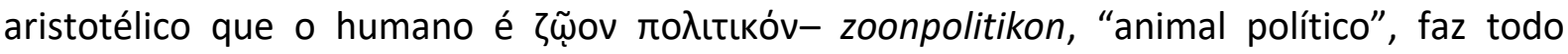
sentido. O humano existe em comunidade, na qual todos fazem parte de todos. Hannah Arendt lembra a famosa recepção da ideia aristotélica em Tomás de Aquino: Homo est naturaliterpoliticus, id est, socialis- "o homem é, por natureza, político, isto é, social". ${ }^{4} \mathrm{Ou}$, como na poesia conhecida de John Donne (1572-1631), "nenhum homem é uma ilha". O "anthropos" é gregário por natureza, e, como bem observado na canção Comida, do grupo musical Titãs, o humano precisa mais do que apenas comida e bebida para se realizar e atingir seu potencial pleno. ${ }^{5}$ Ainda conforme o Estagirita, a felicidade, individual e coletiva, será alcançada pela vivência da ápetń - "virtude" ética em sociedade. Reagindo a seu mestre Platão, que não via diferença entre liderar uma casa e um reino, Aristóteles (1985) apresentou, como era de seu feitio, uma sistematização detalhada das formas de governo, puras e impuras. Não é objetivo deste artigo entrar neste detalhamento ${ }^{6}$. Esta breve apresentação do conceito de política em Aristóteles serve para apresentar a importância da política na vida humana, e introduzir o presente artigo, que tem como objetivo apresentar a denúncia feita pelo teólogo luterano alemão Dietrich Bonhoeffer (1906-1945) de uma deturpação da política, a saber, o messianismo político, que, como se verá, é uma associação impura (para usar uma palavra aristotélica) entre política e religião.

\section{Messianismo político}

A questão do assim chamado messianismo enquanto categoria sociológica é importante por demais para se entender muitas questões históricas na política em geral, e na política brasileira em particular. Neste sentido, o texto clássico no Brasil segue sendo o estudo alentado e detalhado de Maria Isaura Pereira de Queiroz (1965). Para os propósitos do presente artigo, não se entrará na questão da relação entre messianismo e milenarismo, tema

4 ARENDT, Hannah. A condição humana. Rio de Janeiro: Globo, 1988. p. 31.

5 Para a letra da música consultar Comida no sítio Vagalume. Disponível em: <https://www.google.com/search?q=comida+tit\%C3\%A3s\&oq=comida+tit\%C3\%A3s\&aqs=chrome..69i57j46 j016.1830j0j7\&sourceid=chrome\&ie=UTF-8>Acesso: 21 abril 2020

6 Para detalhes, consultar: AZAMBUJA, Darcy. Teoria geral do Estado. Rio de Janeiro: Globo, 1988. SOARES, Mário Lúcio Quintão. Teoria Geral do do Estado. O substrato clássico e os novos paradigmas para o Direito Constitucional. Belo Horizonte: Del Rey, 2001. BONAVIDES, Paulo. Ciência Política. São Paulo: Malheiros, 2014.

Protestantismo em Revista | São Leopoldo | v. 46, n. 01 | p. 50-63| Jan./jun. 2020

Disponível em: <http://periodicos.est.edu.br/index.php/nepp> 
amplamente investigado por muitos antropólogos, cientistas sociais e historiadores. ${ }^{7}$ Os trabalhos nesta área se ocupam de estudar as questões religiosas e a teologia que informou estes vários movimentos. Todavia, o foco do artigo está em verificar a incidência na política brasileira de um messianismo não necessariamente milenarista, mas político, e particularmente, de um tipo de messianismo populista político que utiliza à farta linguagem religiosa.

Todavia, é possível afirmar que é fato que o messianismo na política pode acontecer tanto à direita como à esquerda. Isto porque há na matriz cultural brasileira, no (in)consciente coletivo de não poucos a perspectiva da chegada do "Dom Sebastião" milagroso e poderoso que vai resolver todos os problemas da nação. A esperança no "salvador da pátria" sempre esteve presente na história política brasileira. A crença sebastianista se reflete em muitos momentos da história política brasileira.

\section{Dietrich Bonhoeffer e a crítica ao messianismo político}

Tendo visto, mesmo de maneira resumida, a importância da política para a vida em sociedade e o conceito de messianismo e populismo na política, é chegado o momento apresentar, também em síntese, alguns dados biográficos de Dietrich Bonhoeffer, cujo pensamento teológico será a lente pela qual o messianismo político do atual momento brasileiro será avaliado criticamente. O pressuposto com o qual o artigo trabalhará é que é importante saber do contexto histórico em que Bonhoeffer atuou e produziu sua teologia.

Dietrich Bonhoeffer é, com toda certeza, um dos teólogos mais conhecidos do século 20. Considerado mártir cristão, adquiriu fama pelo seu testemunho na luta contra o regime nazista na Alemanha durante a 2 a Guerra Mundial. Nascido em Breslau (atualmente Wrocław, Polônia), em 4 de fevereiro de 1906, estudou teologia em Tübingen e Berlim. Doutorou-se em 1927, aos 21 anos de idade, com a tese intitulada Sanctorum Communio: uma investigação dogmática sobre a sociologia da igreja, onde se aprofundou no tema da eclesiologia em perspectiva sociológica e teológica. No ano seguinte realizou seu Vikariat - Vicariato, isto é, o Período Prático de Habilitação do Ministério Pastoral ${ }^{8}$ em Barcelona. Em 1929, voltando para Berlim, Bonhoeffer inicia sua pesquisa de Habilitationschrift a fim de ter a possibilidade de se tornar professor numa universidade alemã. Em sua tese de habilitação, Akt und Sein ("Ato e Ser") Bonhoeffer desenvolveu um diálogo entre teologia e filosofia, investigando respeito da busca do ser humano pela verdade. Seu objetivo foi demonstrar como a tradição transcendental de Kant e Hegel e a ontologia transcendental de Heidegger estavam determinando a teologia. Por um lado, criticou as correntes filosóficas provenientes do idealismo filosófico, com seus desdobramentos na compreensão antropológica e a diluição da soteriologia para a esfera mundana, e do outro, advertiu contra a teologia transcendental de

7 Para mais detalhes: NEGRÃO, Lísias Nogueira. Revisitando o messianismo no Brasil e profetizando seu futuro. Revista Brasileira de Ciências Sociais. Vol. 16, N. 46 [online]. Disponível em: <https://www.scielo.br/scielo.php?pid=S0102-69092001000200006\&script=sci_abstract\&tlng=pt> Acesso em: 08 maio 2020.

8 A palavra Vicariato é de uso corrente no contexto do luteranismo alemão. No contexto da IECLB, a Igreja Evangélica de Confissão Luterana do Brasil, usa-se a expressão Período Prático de Habilitação ao Ministério (PPHM). Para detalhes, consultar Apoio para a realização do Período Prático de Habilitação ao Ministério. Disponível em: <https://www.luteranos.com.br/conteudo organizacao/ministerio-habilitacao/apoio-pararealizacao-do-periodo-pratico-de-habilitacao-ao-ministerio-pphm-39508> Acesso em: 08 maio 2020.

Protestantismo em Revista | São Leopoldo | v. 46, n. 01 | p. 50-63| Jan./jun. 2020

Disponível em: <http://periodicos.est.edu.br/index.php/nepp> 
Karl Barth. Tal crítica se explica por sua inserção na tradição da teologia luterana. Bonhoeffer insistia na distinção dos dois regimentos, a saber, o secular e o espiritual, distinção essa importante para depois denunciar o messianismo político do Terceiro Reich. ${ }^{9}$

Em fevereiro de 1930, Bonhoeffer finaliza seu trabalho de habilitação e no dia 18 de julho profere sua palestra inaugural como professor habilitado sob o título: "A questão antropológica na filosofia e teologia contemporânea". Assim, com apenas 24 anos, terminou todo o processo necessário para ser professor acadêmico. Ainda em 1929 havia surgido a possibilidade de uma bolsa de estudos para um período de pesquisas nos Estados Unidos. De setembro de 1930 até junho de 1931 Bonhoeffer realiza suas pesquisas no Union Theological Seminary em Nova York, e passa a participar ativa e apaixonadamente da Abyssinian Baptist Church, uma igreja do Harlem, tradicional bairro negro da Big Apple. A escolha de Bonhoeffer revela muito de seu perfil psicológico e de sua sensibilidade pastoral: ele é um alemão luterano branco de classe alta, um "ariano" típico, frequentando uma igreja de batistas negros pobres. Ali, os desafios sociais enfrentados pela comunidade negra e pobre na sua luta contra o racismo e injustiça social cativaram o jovem teólogo. Segundo Heltzel,

O 'batismo' de Bonhoeffer na igreja negra mudou sua vida para sempre. Nessa enorme igreja batista negra no Harlem, Bonhoeffer ouviu a poderosa pregação do reverendo Adam Clayton Powell (1865-1953), que pregava a boa-nova aos pobres. O púlpito do reverendo Powell era um lugar onde poderosamente se proclamava Jesus, o libertador dos oprimidos. Numa época em que os negros eram linchados em todo o país, Powell pregava apaixonadamente contra o pecado social, o sofrimento e a injustiça, com o que ele oferecia um horizonte de esperança para pessoas pobres do Harlem. ${ }^{10}$

Bonhoeffer, a partir da experiência do Harlem, se torna significativamente mais sensível e crítico a estruturas de exclusão e marginalização de pessoas, ainda mais quando endossadas pela igreja. ${ }^{11}$ No entanto, isso não significou que ele tenha incorporado em seu pensamento os pressupostos da teologia do evangelho social da qual tomou conhecimento a partir de Reinhold Niebuhr e Harry Ward, mas acreditava firmemente numa teologia que estivesse atenta e engajada fronte as questões sociais, políticas e econômicas. ${ }^{12}$

No dia 20 de junho de 1931, diante da situação sócio-política da Alemanha, Bonhoeffer retorna a Berlim e inicia assim, segundo Bethge, a segunda fase de sua carreira teológica, a saber, quando termina sua ênfase nos estudos e pesquisas, passando a se dedicar ao ensino e ao pastorado. Tendo então 25 anos de idade, Bonhoeffer pôde ser ordenado ao ministério pastoral na igreja luterana. Essa nova fase é marcada por uma teologia notoriamente pública mesclada com grande sensibilidade pastoral. Assumindo uma cadeira de Teologia Sistemática na Universidade de Berlim, onde, além de lecionar, tornou-se uma

9 SELL, Wilhelm. Ser humano, ser para a outra pessoa: o significado da antropologia de Bonhoeffer para sua ética. Tese de doutorado (Teologia). São Leopoldo: Faculdades EST, 2019, p. 33-40.

10 HELTZEL, Peter Goodwin. Jesus, o revolucionário: radicalizar a cristologia após Bonhoeffer. In: HOFFMANN, Martin; BEROS, Daniel C.; MOONEY, Ruth; (Eds.). Radicalizando a Reforma: outra teologia para outro mundo. São Leopoldo: Sinodal, 2017. p. 206.

11 WILLIAMS, Reggie. Bonhoeffer's Black Jesus. Harlem Renaissance Theology and an Ethic of Resistance. Waco: Baylor University Press, 2014. p. 10-11.

12 TIETZ, Christiane. Theologian of Resistance. The Life and Thought of Dietrich Bonhoeffer. Minneapolis: Fortress Press, 2016. p. 19-21.

Protestantismo em Revista | São Leopoldo | v. 46, n. 01 | p. 50-63| Jan./jun. 2020

Disponível em: <http://periodicos.est.edu.br/index.php/nepp> 
espécie de capelão para alguns alunos, e ainda assumiu uma vaga pastoral num bairro popular na parte oriental de Berlim. ${ }^{13}$

Nos dois anos em que lecionou na Universidade de Berlim ficou explícita sua constante preocupação com questões teológicas e filosóficas que davam elementos fundantes ao chamado Positives Christentum, "Cristianismo Positivo" ${ }^{14}$, uma revisão do cristianismo à luz de do movimento político nacional-socialista. Durante o semestre de outono-inverno de 1932 e 1933, Bonhoeffer apresenta as preleções sobre criação e queda, com base nos três primeiros capítulos do Gênesis. Estas palestras foram publicadas na Alemanha em forma de livro com o título Schöpfung und Fall, e no Brasil, "Criação e queda". ${ }^{15}$ É justamente neste período, no dia 30 de janeiro, que Adolf Hitler foi eleito chanceler na Alemanha. O país sofria com superinflação, e a República de Weimar entrou em crise. Havia um temor generalizado na sociedade que uma "revolução bolchevique" poderia tomar o poder. Neste contexto Hitler experimenta sua ascensão ao poder. Dois dias depois, dia 1 de fevereiro de 1933, Bonhoeffer, tendo aceitado um convite anterior à eleição de Hitler, discursa numa emissora de rádio criticando duramente o título de Führer (guia) o qual estava sendo amplamente atribuído a Hitler e, num jogo de palavras na língua alemã, o chama de Verführer (sedutor). O título da "fala" de Bonhoeffer na emissora de rádio era provocante: "O conceito alterado de Führer da geração jovem". Quando Bonhoeffer fez o mencionado jogo de palavras um funcionário da emissão imediatamente cortou o som do seu microfone. ${ }^{16}$

O conceito de Führer é anterior a Hitler. Já em 1902, Georg Ritter von Schönerer, um nobre de extrema direita da Áustria que lutava pela integração de seu país ao reino alemão, após um discurso no Parlamento, é chamado de Führer por seus seguidores. Foi Schönerer também que na ocasião evoca publicamente pela primeira vez a saudação "Heil!", "salve", ao declarar sua lealdade à família real alemã ao invés da austríaca dos Habsburgo: "Salve os Hohenzollern!" O pangermanismo de Schönerer influenciou a compreensão política de Hitler, austríaco por nascimento, além das músicas de Richard Wagner, cujas óperas romantizavam as lendas germânicas que descreviam seus heróis desmedidos. Hitler também considerava a monarquia dos Habsburgo como opressora à raça germânica. Em 1913, ele se muda para Munique, Alemanha, e durante o período da Primeira Guerra se alistou como voluntário no exército bávaro, sendo recrutado no dia 16 de agosto do mesmo ano. Pelos seus quatro anos de serviços foi promovido a cabo e recebeu duas condecorações por bravura, a segunda delas a Cruz de Ferro, ironicamente por recomendação de um oficial judeu. No tempo em que se recuperava dos ferimentos por causa de um ataque com gás tóxico no hospital militar em Pesewalk, na Pomerânia, Hitler ficou sabendo da derrota da Alemanha. A culpa naturalmente, como era comum entre os nacionalistas exaltadores da raça germânica, caiu principalmente sobre os judeus. Mas antissemitismo não era algo novo. Ele já está bastante evoluído no período de Otto von Bismarck (1815-1898), tido como herói do germanismo por ter idealizado

13 BETHGE, Eberhard. Dietrich Bonhoeffer: A Biography. Minneapolis: Augsburg Fortress, 2000. p. 207-211.

14 Para uma apresentação breve do Cristianismo Positivo consultar CALDAS, Carlos. "Não posso suportar iniqüidade associada a ajuntamento solene". O "Cristianismo Positivo" tupiniquim. 25 abril 2020. IHU Online. Disponível em <http://www.ihu.unisinos.br/78-noticias/598306-nao-posso-suportar-iniqueidade-associadaao-ajuntamento-solene-o-cristianismo-positivo-tupiniquim> Acesso: 8 de maio 2020.

15 BONHOEFFER, Dietrich. Criação e queda. Uma interpretação teológica de Gênesis 1-3. São Leopoldo: Sinodal, 2020.

16 SCHLINGENSIEPEN, Ferdinand. Dietrich Bonhoeffer 1906-1945: Martyr, Thinker, Man of Resistance. London: T \& T Clark, 2010. p. 117.

Protestantismo em Revista | São Leopoldo | v. 46, n. 01 | p. 50-63| Jan./jun. 2020

Disponível em: <http://periodicos.est.edu.br/index.php/nepp> 
o 2o Reich (1871-1918), que significou a unificação dos territórios alemãs em 1871. Seu desprezo pelo liberalismo, socialismo, parlamentarismo, igualitarismo e outros conceitos modernos, juntamente com forte antissemitismo, passou a ser, após a derrota na Primeira Guerra, como chave de sucesso para o Terceiro Reich. Havia um forte anseio por um líder aos seus moldes que devolvesse à Alemanha sua soberania. Ao mesmo tempo, a credibilidade da recém fundada República de Weimar, que tinha com objetivo estabilizar o Estado alemão e sua economia, estava desmoronando. As sanções impostas no Tratado de Versalhes, que previa reparações financeiras pelos danos causados na Primeira Guerra, causavam forte desgosto por dificultar a recuperação e engrandecimento do Estado alemão. Assim, os discursos acerca de um renascimento do espírito nacional alemão em uma comunidade nacional germânica se fortificavam. É precisamente esse conjunto de situações que tornou fértil a possibilidade de fecundar e desenvolver um movimento político-messiânico. ${ }^{17}$

Hitler entrou para a política após participar de cursos de instrução política ofertado pelo Exército alemão. Ideais como o germanismo e arianismo eram ressaltados e, enquanto isso, os judeus foram considerados culpados por destruir o meio de vida dos trabalhadores "arianos" ao usarem o capital de forma improdutiva. Em pouco tempo Hitler se tornou membro do Partido dos Trabalhadores Alemães, destacando-se pela eloquência de seus discursos. Em fevereiro de 1920 o partido muda de nome para Partido Nacional-Socialista dos Trabalhadores Alemães. No entanto, apesar de no nome constar o termo "socialista", é equivocado ver o nazismo como forma do socialismo ${ }^{18}$. Sua retórica igualitária e social acima do indivíduo e do acúmulo de capital estavam somente relacionados ao conceito de raça e povo. Hitler era totalmente contrário aos ideais comunistas e aos da socialdemocracia. Os sociais-democratas eram considerados traidores por terem assinado o Tratado de Versalhes. ${ }^{19}$

A política do novo chanceler revestia o movimento nacionalista de um caráter fortemente religioso. A partir de 1933 Hitler passa a utilizar cada vez mais o título de Führer, e o nacional-socialismo prometia a salvação política e econômica ligada a uma renovação cultural-cristã, esta cada vez mais despida dos aspectos judaicos e com forte ênfase no Jesus ariano - marcas do mencionado "Cristianismo Positivo". Em 28 de fevereiro foi declarado estado de emergência e no dia 24 de março se instaurou a Lei da Autoridade Plena, que extinguiu qualquer controle político por parte do Parlamento. Duas semanas depois é instituído o assim chamado "Parágrafo Ariano", que estabelecia a demissão de todos os funcionários de fé e ascendência judaica de órgãos públicos. ${ }^{20}$ Diante dessa situação, Bonhoeffer é um dos primeiros teólogos que falou sobre a igreja e a nova situação dos judeus. Segundo ele, essa situação colocava diante da igreja três tarefas frente ao Estado: primeira, perguntar se seu poder e sua ação são legitimas; segunda, se há um envolvimento e comprometimento da igreja com as vítimas, não importando se são ou não pertencentes à

17 EVANS, Richard J. A chegada do Terceiro Reich. São Paulo: Planeta, 2003. p. 82-85.

18 Durante a campanha eleitoral presidencial no Brasil em 2018 foi amplamente divulgada em praticamente todas as mídias e redes sociais o discurso "nazismo é de esquerda". Este discurso foi difundido para levar a crer que todas as formas de pensamento político de tendência esquerdista são ontológica e inerentemente malignas, e que a "salvação" do Brasil estaria em um candidato da extrema direita.

19 EVANS, 2003, p. 217-229.

20 BETHGE, 2000, p. 272-274.

Protestantismo em Revista | São Leopoldo | v. 46, n. 01 | p. 50-63| Jan./jun. 2020

Disponível em: <http://periodicos.est.edu.br/index.php/nepp> 
igreja; e, terceira, além de cuidar das vítimas ela precisa ativamente se envolver com o objetivo de "travar a roda" do mal. ${ }^{21}$

Para Bonhoeffer estava claro que era dever da igreja se envolver ativamente nas questões políticas. O objetivo não é ter o poder do Estado em suas mãos, mas de exigir justiça e boa administração política. No entanto, a posição de Bonhoeffer gerou desconforto e encontrou oposição dentro da própria igreja. A maioria dos membros da igreja se mostrava favorável ao governo, e passou a se denominar Deutsche Christen, "teuto-cristãos". Bonhoeffer passou então a distribuir folhetos com conteúdos de oposição e crítica a tal posicionamento, pedindo reuniões de protesto, e chegou até mesmo a planejar uma greve de pastores. No entanto, em julho do mesmo ano, 1933, Ludwig Müller é eleito Reichsbischof, "bispo do Reich" (ou "bispo do governo") com 70\% dos votos e teve como principal objetivo assimilar o "princípio do Führer" à igreja e à educação religiosa. ${ }^{22}$

Para Bonhoeffer estava claro que quando a igreja assumiu o Arierparagraph, o "Parágrafo Ariano", ela deixou de ser cristã. Como permanecer numa igreja que deixou de ser cristã? Essa é a pergunta que ele faz por carta a Karl Barth. ${ }^{23}$. A ideia compartilhada por muitos de ser uma igreja livre era atraente. Havia um status confessionis, ou seja, o que estava em jogo era a própria natureza da igreja. Barth estava de acordo. Isso fez com que Bonhoeffer se envolvesse mais ainda nas questões políticas de seu país. Quanto a isso,

Em abril daquele ano, Bonhoeffer publicou seu ensaio Die Kirchevor der Judenfrage (“A igreja e a questão judaica"), em resposta ao Parágrafo Ariano. Nesse texto, uma reflexão verdadeiramente seminal, publicado na íntegra no jornal Vormarsch, Bonhoeffer faz o que se conhece por teologia política, pois literalmente conjuga teologia e política, de uma maneira virtualmente impensável para a teologia luterana da época, tendo em vista que ele critica o Estado e, ainda mais difícil, o faz em defesa do povo judeu. Quanto a isso, há que se lembrar que o luteranismo abraçou o conceito de dois reinos de Lutero: um, o reino temporal, o Estado, responsável pelas questões sociais e políticas; e o outro, o reino espiritual, a Igreja, responsável pelas almas dos homens e os assuntos espirituais em geral. Com base na doutrina dos dois reinos, a Igreja não deveria interferir em questões de natureza política. Foi exatamente nesse ponto que Bonhoeffer ousou romper com o modelo de teologia luterana praticado na Alemanha de seu tempo. Ele o fez em termos contundentes, chamando esse tipo de teologia de "pseudoluteranismo". Nesse sentido, não há como negar que Bonhoeffer praticou uma teologia pública, pois tratou da questão do dia, por assim dizer, em discussão na sociedade alemã da época, em perspectiva de uma teologia profética de denúncia do mal. Bonhoeffer alerta para o perigo de a Alemanha tornar-se um Unrechtsstaat - "Estado de injustiça". ${ }^{24}$

21 BONHOEFFER, Dietrich. Dietrich Bonhoeffer Works [DBWE]. Vol. 12. The Church and the Jewish Question. Minneapolis: Fortress Press, 2009. p. 361-370. A expressão "travar a roda" do mal vem de um dito de Bonhoeffer que se tornou muito conhecido, quando falou sobre a necessidade de se colocar Dem Rad in die Speichenfallen ("uma trava nos (entre) os raios da roda"). Neste dito, Bonhoeffer afirma que não é suficiente aplicar um curativo nas vítimas dos que foram atropeladas pelas rodas da injustiça, mas, mais que isso, tomar uma ação concreta que impeça o carro de continuar andando. "A metáfora aponta para colocar-se nas rodas da injustiça para fazer o carro da maldade parar de andar". CALDAS, Carlos. Religião e política em Dietrich Bonhoeffer. Inter-Legere. Revista do Programa de Pós-Graduação em Ciências Sociais da UFRN. No 17, agodez 2015. p. 25.

22 TIETZ, 2013, p. 37.

23 BONHOEFFER, 2009b. p. 164.

24 CALDAS, 2015, p. 24-25.

Protestantismo em Revista | São Leopoldo | v. 46, n. 01 | p. 50-63| Jan./jun. 2020

Disponível em: <http://periodicos.est.edu.br/index.php/nepp> 
Em julho de 1933, Bonhoeffer fez parte de um grupo de pastores e teólogos que, sob a liderança de Friedrich von Bodelschwingh trabalhou pra produzir uma confissão teológica que fosse relevante naquele momento histórico. A versão final deste documento foi publicada no final do ano e ficou conhecida como a Confissão de Bethel. No entanto, Bonhoeffer não assinou o documento, por considerar sua versão final muito acrítica quanto ao que considerou uma falta de distinção sobre a teologia natural. Na versão anterior do documento, de agosto, havia uma crítica mais clara à teologia natural que compreendia ser possível a revelação específica soteriológica de Deus na criação e na história além da pessoa de Jesus Cristo. ${ }^{25}$ É justamente essa distinção entre as formas como Deus se revela na história que serve de fundamentação para Bonhoeffer estabelecer sua crítica ao messianismo religioso de seu tempo.

\section{Questões teológicas frente ao messianismo religioso}

Para Bonhoeffer estava claro que a igreja de seu contexto, seduzida pelo discurso político nacionalista, havia perdido sua vocação. Por isso, não deve ser visto como acaso o fato de que nos anos de 1932 e 1933 ele tenha se dedicado ao tema da igreja e seu caráter mundano. Para ele, o lugar da igreja no mundo é o lugar do próprio Deus, e essa não é uma afirmação secundária, mas deve ser o pressuposto e o objeto de toda reflexão teológica. $A$ partir dessa afirmação, que aparece em seu seminário sobre "A essência da igreja", dado no semestre do verão de $1932,{ }^{26}$ é possível perceber a preocupação de Bonhoeffer em distinguir e localizar a igreja no mundo.

A igreja é criada pela auto-revelação de Deus em Jesus Cristo. No entanto, Igreja não é simplesmente aquela que se chama de igreja, ou que recita credos, consagra bispos ou que prega a doutrina da justificação de Lutero. Igreja é a humanidade recriada por Cristo por meio de sua morte e ressurreição. É o novo povo, nova sociedade, que está debaixo do seu senhorio e está determinada em evidenciar essa nova realidade. No entanto, isso também significa que "Cristo não é o fundador de uma nova religião e de uma comunidade religiosa. Ele é o Redentor, a fundação da Igreja, não o fundador. (...) Cristo é a nova humanidade. Cristo é simultaneamente a fundação, o início e o cumpridor da Igreja". ${ }^{27}$ Essa nova humanidade em Cristo é a Igreja que, pelo agir do Espírito Santo, atualiza, sempre de novo, a sua presença no mundo.

No entanto, diferente do que previa Schleiermacher, a igreja não é a comunidade formada de indivíduos piedosos, reunidos em torno de um mesmo ideal. Ela não deriva de um desejo em comum, mas ela é ação e a concretização do próprio Deus que não abandona aquilo que é seu. Nesse sentido, é importante lembrar que a igreja, como se constitui, não é pura, mas ela permanece sob o signo do pecado. Bonhoeffer quer assim indicar que não é a pureza

25 TIETZ, 2013, p. 41.

26 No contexto político dessas preleções estava a queda do Chanceler Heinrich Brüning e a sugestão de seu sucessor, Franz von Papen, de estabelecer um Estado "cristão". Para Bonhoeffer, o novo Chanceler nada mais era do que o precursor da ditadura de Hitler. No entanto, ele não assume publicamente um partido contrário ao novo governo. Antes, sua postura crítica se dava a partir da sua distinção entre igreja e Estado, estabelecendo para isso a natureza da igreja e sua vocação política. Segundo seu aluno Otto Dudzus, esta preleção foi o primeiro curso que ele oferecia com resultados práticos.

27 BONHOEFFER, Dietrich. Dietrich Bonhoeffer Works [DBWE]. Vol. 11. The Nature of the Church. Minneapolis: Fortress Press, 2012. p. 301.

Protestantismo em Revista | São Leopoldo | v. 46, n. 01 | p. 50-63| Jan./jun. 2020

Disponível em: <http://periodicos.est.edu.br/index.php/nepp> 
de seus membros que dignifica ou forma a igreja. A igreja é mundana no seu sentido mais próprio e, por isso, ela não promove a fuga de seus membros do mundo em direção ao transcendente, mas ela, pela fé, encarna o Cristo que lança luz sobre toda a realidade, também sobre o Estado. Isso não quer dizer que a igreja tenha a autoridade de interferir no Estado. $O$ Estado é estabelecido como um aviso crítico à igreja de que Deus não deu a ela a espada do poder. "A sua espada é a palavra e a oração. Desse modo, serve ao Estado. Quando é ameaçada pelo Estado, luta contra o Estado. Não tentará governar o Estado. Seu objetivo é a proclamação do senhorio de Cristo sobre o mundo inteiro em fé e na palavra". ${ }^{28}$ Ou seja, tanto a igreja quanto o Estado têm atribuições específicas que precisam ser administradas com responsabilidade e objetividade. Por tal razão, não é atribuição do Estado ser cristão ou ateu.

Já no semestre de inverno entre 1932 e 1933 a preocupação com a confusão nacionalista sobre as "ordens da criação" está presente nas aulas de Bonhoeffer, especialmente em "Criação e queda". Na esteira teológica de Lutero, Bonhoeffer afirma não ser possível um conhecimento natural pleno de Deus. Todo o saber natural, sem a revelação específica, termina em idolatria e está sob a acusação da lei. O elo entre criação e redenção se encontra em Jesus Cristo e a criação não pode ser confundida com Deus e nem a ela pode ser conferida um caráter redentor. A criação não é boa por si mesma, mas por causa daquele que a testifica e a mantém. Assim, Bonhoeffer lida com a criação não somente protologicamente, mas principalmente pelo viés escatológico e, por isso, "realoca toda a revelação de Deus para Jesus Cristo, desabsolutizando as ordens da criação como esferas autônomas, fixas e isoladas de valor revelatório.

É por essa razão que Bonhoeffer não avaliza o conceito da creatio continua mesmo sendo termo comum à tradição luterana e ter sido usado por Lutero, de tal forma como seu contexto o teológico pende a considerar, a saber, cedendo a uma espécie de sinergismo entre Deus e o mundo, entre a fé e as obras. Desconsiderando-se que há uma descontinuidade entre criação e redenção, passa-se facilmente a considerar a redenção pelo viés da revelação natural. Por isso, Bonhoeffer troca o termo creatio continua e insiste na compreensão de uma criação conservada, evita o termo ordens da criação e sugere ordens da preservação. ${ }^{29}$

Ainda no final de 1932, na palestra conferida em um retiro devocional do Instituto Protestante de Educação Continuada para Mulheres, sob o título Venha Senhor o teu Reino Bonhoeffer argumenta que orar "venha o teu reino" significa orar para que o Reino de Deus se estabeleça na terra. ${ }^{30}$ Nessa palestra, ele descreve a igreja e o Estado como duas formas do Reino de Deus na terra e, ao mesmo tempo, explica sua relação mútua e necessária. Godsey situa as três argumentações de Bonhoeffer: primeiro, Deus considerou a sua criação como boa e a abençoou; segundo, por causa da desobediência e a queda, Deus amaldiçoou a terra, fazendo com que ela passe a carregar espinhos e cardos, o rosto de Deus se torna oculto de sua criatura e o ser humano é escravizado pelos poderes da morte; terceiro, Jesus Cristo, o próprio filho de Deus, encarnado, veio a essa terra amaldiçoada, foi crucificado na "arvore da maldição", rompendo por meio da ressurreição com sua maldição.

28 BONHOEFFER, 2012, p. 332.

29 BONHOEFFER, 2020, p. 51. Para mais detalhes consultar: SELL, 2019, p. 134-142.

30 BONHOEFFER, Dietrich. Thy Kingdom Come! In GREEN, Clifford J; DEJONGE, Michael P. The Bonhoeffer Reader. Minneapolis: Fortress Press, 2013. p. 340-351.

Protestantismo em Revista | São Leopoldo | v. 46, n. 01 | p. 50-63| Jan./jun. 2020

Disponível em: <http://periodicos.est.edu.br/index.php/nepp> 
Nesse milagre da ressureição, pelo qual Deus pronuncia um intenso "sim!” para o mundo, o Reino de Deus veio à terra. A vinda do Reino de Deus, enfatiza Bonhoeffer, não significa nada além da vinda do próprio Deus, e sua vinda em Cristo não significa apenas uma ruptura e destruição da maldição, mas, ao mesmo tempo, uma afirmação da terra, uma entrada em suas ordens, suas comunidades, sua história. ${ }^{31}$

Para Bonhoeffer, o Reino de Deus na terra, na realidade penúltima, assume duas formas: a igreja e o Estado. Ambos estão ligados e não podem ser isolados, nem separados, mas distintos em sua função. Na igreja, o Reino de Deus assume sua forma na medida em que ela testemunha o Evangelho do milagre da nova criação de Deus. No Estado, o Reino de Deus assume sua forma na medida que ele preserva a ordem da antiga criação.

Assim, a igreja testemunha a superação do poder da morte pelo milagre da ressureição; o Estado mantém a ordem da preservação da vida. Na igreja, o poder da solidão é vencido pelo milagre da confissão e perdão, e pela criação de uma nova comunidade; no Estado, as ordens da sociedade, casamento, família, pessoas são preservadas no mundo da maldição. Na igreja, a sede do homem egocêntrico por seu próprio ser é superado pela proclamação da cruz e ressureição de Cristo e é transfigurado numa sede amorosa pelo outro, a saber, por Deus e pelo irmão; no Estado, a sede do homem, que pode indicar o bem e o mal para os outros, é ordenada e contida pela autoridade responsável. A partir disso, fica claro, portanto, que a igreja limita o Estado e o Estado limita a igreja. Ambos devem permanecer conscientes dessa limitação mútua e suportar a tensão existente lado a lado sem ultrapassar os limites entre eles. ${ }^{32}$

Bonhoeffer chama a atenção para o fato que a igreja não deve aspirar tomar sobre si o poder do Estado, nem mesmo a governança é feita por meio de seu específico. Da mesma forma, o Estado não deve ter aspirações religiosas e soteriológicas, pois sua função é manter a ordem e a boa administração da coisa pública para o bem de todas as pessoas. Por isso, só é possível orar pela vinda do Reino de Deus de forma plena e última quando de forma penúltima se está submetido aquilo que foi inaugurado na encarnação, morte e ressurreição de Cristo, ou seja, ao Deus que veio e assume aquilo que é seu. Os dois reinos são a dupla atividade de Deus, assim, estão conectados. ${ }^{33}$ Os dois regimentos são a atividade de Deus enquanto preservador e redentor, e nele o Estado e a igreja desempenham papeis importantes.

Como bem lembra DeJonge, esse conceito de dois regimentos quando surgiu com Lutero era usada quando fosse necessário lembrar as autoridades políticas de sua função, ou seja, que deveriam se concentrar em governar com zelo, e não se envolver em questões doutrinárias; por seu turno, também lembrar aos bispos que sua função apropriada para se concentrarem com zelo seria a proclamação do Evangelho, e não os detalhes da política e da

31 GODSEY, John D. The Theology of Dietrich Bonhoeffer. Oregon: Wipf \& Stock, 2015. p. 107-108.

32 GODSEY, 2015, p. 108.

33 Aqui é importante fazer um comentário. Nesse escrito, Bonhoeffer vai "reduzir" o reino temporal ao Estado. No entanto, em outros momentos, especialmente em sua obra Ética, ele vai ampliar e particionar nos mandatos: família, cultura e governo. DeJonge lembra que em Bonhoeffer os dois reinos não são reduzidos a uma doutrina de igreja e Estado, pois este último não é o único agente de preservação no reino temporal (a família é outra), e a igreja como instituição tem um lugar não apenas no reino espiritual, mas também no reino temporal. BONHOEFFER, Dietrich. Ética. 9a edição. São Leopoldo: Sinodal, 2009. p. 180-183. DEJONGE, Michael P. Bonhoeffer on Resistance: The Word Against the Wheel. New York: Oxford University Press, 2018. p. 37-38.

Protestantismo em Revista | São Leopoldo | v. 46, n. 01 | p. 50-63| Jan./jun. 2020

Disponível em: <http://periodicos.est.edu.br/index.php/nepp> 
administração da coisa publica, querendo tomar para si a sua administração. Isso não significa uma separação rígida entre os dois regimentos. Esses dois, assim como Lei e Evangelho, são distintos para que possam trabalhar juntos. ${ }^{34}$

O problema de Bonhoeffer com aqueles que ele chamou de pseudo-luteranos foi o fato de que estes interpretavam os dois regimentos em rígida separação fazendo com que a ideia de volk passasse a ser encarado como uma ordem da criação. A igreja passou então a avalizar as ações inescrupulosas do Estado nazista, ao considerar que o reino temporal desfruta de uma autonomia não apenas da igreja, mas também do governo de Deus em Cristo. Isso significa que ela fica livre para confiar em suas próprias regras e normas derivadas da lei natural ou daquilo que considera ordens da criação. Bonhoeffer é crítico a essa posição, pois essa independência significava também uma autorização divina, pelas ordens constituídas, de gerenciar a partir dos próprios ideais nacionalistas ligados a ideia de um povo de uma só raça, o qual justifica a guerra afirmando que o amor pelo volk santificará o assassinato. Diante disso, o insight de Bonhoeffer foi lembrar as ordens em seu estado original e em seu estado caído. Por causa do pecado, a tentativa de ler a vontade de Deus diretamente na criação resulta na idolatria e na auto-justificação. Ou seja, o Estado se diviniza e usurpa o direito de Deus sobre a vida, além de tomar sobre si características messiânicas flagrantes no discurso político.

É diante dessa situação que Bonhoeffer muda o termo ordens da criação para ordens da preservação. O objetivo foi recuperar o pensamento genuíno dos dois reinos fazendo com que se mine a separação total dos reinos e faz com que uma leitura sobre a vontade de Deus nos processos supostamente naturais não seja mais avalizadas pela igreja, a exemplo da ideia de volk. "Tudo que pode ser lido da natureza deve passar pela lógica de que a igreja sabe sobre a natureza, a saber, que é uma criação caída e preservada para a redenção". ${ }^{35}$ A redenção só existe ali onde Deus se revelou, em Jesus Cristo. O encarnado, morto e ressurreto é o lugar onde Deus quer ser encontrado. Apesar de que Deus possa ser tateado na natureza, ali ele somente se faz presente de maneira preservadora, e esta sempre estará direcionado para o fim, ou seja, para Jesus Cristo.

\section{Considerações finais: Bonhoeffer e o messianismo político no Brasil contemporâneo}

Tendo visto a maneira pela qual Bonhoeffer criticou uma relação promíscua entre igreja e Estado, é notório como seu legado teológico serve de crítica ao messianismo político presente no Brasil contemporâneo. Portanto, tal como afirmado na introdução do presente artigo, na história política do Brasil vários líderes já foram vistos como o "Dom Sebastião", o único capaz de salvar o país - Vargas, Kubitschek, Jânio, Collor de Melo, Lula da Silva e, agora, Jair Messias Bolsonaro. Este último, por coincidência irônica, tem "Messias" no nome, e assim tem sido visto por muitos, como o "salvador da pátria", o único capaz de impedir que o Brasil seja tomado por uma revolução comunista, e limpar o país da corrupção. Tal como visto anteriormente, Adolf Hitler foi visto de maneira semelhante na Alemanha na década de 1930. Quanto isso, anotou-se:

Imagens de apoio a Bolsonaro com linguagem religiosa estão sendo amplamente divulgadas nas redes sociais. Em uma, que emula a cena dos Evangelhos em que

34 DEJONGE, 2018, p. 38.

35 DEJONGE, 2018, p. 43.

Protestantismo em Revista | São Leopoldo | v. 46, n. 01 | p. 50-63| Jan./jun. 2020

Disponível em: <http://periodicos.est.edu.br/index.php/nepp> 
Pedro afunda no Mar da Galileia, mas Jesus o resgata, Jesus aparece segurando o braço de Bolsonaro dizendo: "Coragem Capitão, temos um país inteiro para salvar". Em outra, aparece uma foto de Bolsonaro e Michele, sua esposa, ambos com a fronte ligeiramente encurvada e olhos fechados, em uma típica postura de prece, e tendo ao fundo uma imagem de Jesus com o Sagrado Coração, encimada pelos dizeres "Ele sofre por nós. Ele levou uma facada por nós. Ele veio para salvar os brasileiros. Mas vai salvar o mundo", e na parte de baixo da montagem as frases "A cura não é dos cientistas. A cura não é dos médicos. A cura não é dos governadores. A cura é de Bolsonaro". A única palavra que pode ser usada em uma análise desta imagem em perspectiva teológica é: idolatria. Bolsonaro está sendo literalmente idolatrado. Surgiu uma nova religião no Brasil: a bolsonarolatria, o credo dos bolsonarólatras. ${ }^{36}$

No Brasil do primeiro semestre de 2020 , em plena crise mundial provocada pela pandemia do coronavírus, um grupo evangélico brasileiro denominado Coalizão pelo Evangelho ${ }^{37}$ publicou nas redes sociais um manifesto no qual há críticas ao que seus integrantes chamam de "endeusamento da ciência" 38 , além de criticarem as medidas de isolamento social, com a alegação que estas medidas estariam prejudicando a economia. Um documento com tal teor, formulado por algumas figuras muito conhecidas no meio evangélico brasileiro, que segue acriticamente o discurso do atual presidente da República, é um ato ao mesmo tempo político e religioso, que faz lembrar as ações dos Deutsche Christen.

No entanto, há aqui uma diferença que precisa ser mencionada. Diferente do que aconteceu no Brasil nas últimas eleições, a igreja alemã não promoveu ativamente a eleição de Hitler. O problema da igreja alemã foi a sua omissão voluntária diante dos rumos políticos de seu país, baseado numa compreensão equivocada da teologia dos dois reinos, a qual separava totalmente igreja e Estado, causada pela Eigengesetzlichkeit (autonomia) do mundo diante da lei de Deus. Nesta direção, a igreja proporcionou a fundamentação teológica baseada nesta compreensão para sustentar a ideologia nazista, além de permitir e auferir um caráter messiânico "natural" ao Führer. No Brasil, o equívoco está igualmente na falta de distinção entre igreja e Estado, mas agora promovendo sua indevida fusão, onde muitas igrejas auferem a Bolsonaro a compreensão de ser um enviado por Deus para pôr ordem a uma nação terrena. O slogam "Brasil acima de tudo, Deus acima de todos" em sua campanha eleitoral já evocava tal compreensão, aliada a promessa de maior participação das igrejas nos rumos do país. Fazendo uma "bricolagem" religiosa-confessional ao ser re-batizado por um pastor evangélico no Rio Jordão mesmo permanecendo católico, Bolsonaro conseguiu

36 CALDAS, 2020.

37 Coalizão pelo Evangelho é a versão brasileira do movimento The Gospel Coalition (TGC), uma rede de igrejas de matriz teológica reformada que pretende oferecer às igrejas subsídios para atuar na transformação da cultura. Para detalhes, consultar: <thegospelcoalition.org>

38 É no mínimo estranho que um grupo que alega ser calvinista critique um "endeusamento da ciência", pois a tradição calvinista preza a doutrina da graça comum, que ensina justamente a ação de Deus na história por meio de agentes não necessariamente religiosos. Calvinistas de pura cepa gostam de destacar que sua tradição teológica impulsionou o desenvolvimento da ciência moderna. Diante deste legado histórico, é tremendamente incoerente que líderes eclesiásticos evangélicos brasileiros "calvinistas" critiquem os governadores de estado no Brasil por decretarem medidas de isolamento social, medidas estas recomendadas pela Organização Mundial de Saúde. As autoridades governamentais brasileiras que levam a sério o que médicos, biólogos, microbiólogos, bioquímicos e outros cientistas recomendam estariam promovendo, na visão da Coalizão pelo Evangelho no Brasil um "endeusamento da ciência".

Protestantismo em Revista | São Leopoldo | v. 46, n. 01 | p. 50-63| Jan./jun. 2020

Disponível em: <http://periodicos.est.edu.br/index.php/nepp> 
legitimar as aspirações messiânicas que resultou em grande parte na sua eleição e, posteriormente, na manutenção de seu poder.

Diante da análise feita acerca das reflexões teológicas de Bonhoeffer é possível formular uma crítica ao endeusamento que se vê no Brasil hoje a um líder político, a despeito das diferenças gritantes que há entre os discursos e ações deste líder com os princípios do evangelho do Messias Jesus de Nazaré. ${ }^{39}$ Novamente a falta de distinção entre igreja e Estado é flagrante. Ao mesmo tempo, grande parte da igreja evangélica, seduzida pela ideia de um Estado mais cristão, se perdeu de sua vocação política diante do Estado em exigir justiça e boa administração da coisa pública. Isso decorre de uma igreja que se perdeu de sua natureza. De fato, há necessidade que se levante no Brasil uma Bekennende Kirche, uma "Igreja Confessante", como nos dias de Bonhoeffer, uma igreja que compreenda, teologicamente falando, a distinção entre igreja e Estado, e a partir de tal compreensão atue, não como uma serva acrítica dos poderes políticos, mas como agente da graça de Deus no mundo.

\section{Referências}

ARENDT, Hannah. A condição Humana. Rio de Janeiro: Globo, 1988.

ARISTÓTELES. Política. Traduzido por Mário da Gama Kury. Brasília: Editora da UnB, 1985.

AZAMBUJA, Darcy. Teoria geral do Estado. Rio de Janeiro: Globo, 1988.

BETHGE, Eberhard. Dietrich Bonhoeffer: A Biography. Minneapolis: Augsburg Fortress, 2000. BONAVIDES, Paulo. Ciência Política. São Paulo: Malheiros, 2014.

BONHOEFFER, Dietrich. Criação e queda. Uma interpretação teológica de Gênesis 1-3. São Leopoldo: Sinodal, 2020.

BONHOEFFER, Dietrich. Dietrich Bonhoeffer Works [DBWE]. Vol. 11. The Nature of the Church. Minneapolis: Fortress Press, 2012.

BONHOEFFER, Dietrich. Dietrich Bonhoeffer Works [DBWE]. Vol. 12. The Church and the Jewish Question. Minneapolis: Fortress Press, 2009.

BONHOEFFER, Dietrich. Ética. 9ạ edição. São Leopoldo: Sinodal, 2009.

BONHOEFFER, Dietrich. The Nature of the Church. In The Bonhoeffer Reader., Clifford J, DEJONGE, Michael P. (Orgs.) Minneapolis: Fortress Press, 2013.

BONHOEFFER, Dietrich. Thy Kingdom Come! In GREEN, Clifford J; DEJONGE, Michael P. The Bonhoeffer Reader. Minneapolis: Fortress Press, 2013.

CALDAS, Carlos. "Não posso suportar iniqüidade associada a ajuntamento solene". O "Cristianismo Positivo" tupiniquim. 25 abril 2020. IHU Online. Disponível em $<$ http://www.ihu.unisinos.br/78-noticias/598306-nao-posso-suportar-iniqueidade-

associada-ao-ajuntamento-solene-o-cristianismo-positivo-tupiniquim> Acesso: 8 de maio 2020.

CALDAS, Carlos. Microética evangélica e gestos de efeito: ingredientes para adesão ao governo Bolsonaro. IHU Online. 10 outubro 2019. Disponível em

39 Quanto a isso, consultar CALDAS, 2019.

Protestantismo em Revista | São Leopoldo | v. 46, n. 01 | p. 50-63| Jan./jun. 2020

Disponível em: <http://periodicos.est.edu.br/index.php/nepp> 
$<$ http://www.ihu.unisinos.br/159-noticias/entrevistas/593336-microetica-evangelica-egestos-de-efeito-ingredientes-para-adesao-ao-governo-bolsonaro-entrevista-especial-comcarlos-caldas> Acesso em 16 maio 2020.

CALDAS, Carlos. Religião e política em Dietrich Bonhoeffer. Inter-Legere. Revista do Programa de Pós-Graduação em Ciências Sociais da UFRN. No 17, ago-dez 2015, p. 17-40.

DEJONGE, Michael P. Bonhoeffer on Resistance: The Word Against the Wheel. New York: Oxford University Press, 2018.

DUCHROW, Ulrich. Os dois reinos. Uso e abuso de um conceito teológico luterano. São Leopoldo: Sinodal, 1987.

EVANS, Richard J. A chegada do Terceiro Reich. São Paulo: Planeta, 2003.

GODSEY, John D. The Theology of Dietrich Bonhoeffer. Oregon: Wipf\& Stock, 2015.

HANSEN, Guillermo. La crítica cristológica de Bonhoeffer a la hermenêutica 'pseudoluterana' de las esferas. Numen. Revista de Estudos e Pesquisa de Religião, Juiz de Fora, v. 6, n. 1, p. 3178, 2003.

HELTZEL, Peter Goodwin. Jesus, o revolucionário: radicalizar a cristologia após Bonhoeffer. In: HOFFMANN, Martin; BEROS, Daniel C.; MOONEY, Ruth; (Eds.). Radicalizando a Reforma: outra teologia para outro mundo. São Leopoldo: Sinodal, 2017.

NEGRÃO, Lísias Nogueira. Revisitando o messianismo no Brasil e profetizando seu futuro. Revista Brasileira de Ciências Sociais. Vol. 16, N. 46 [online]. Disponível em: $<$ https://www.scielo.br/scielo.php?pid=S0102-

69092001000200006\&script=sci abstract\&tlng=pt> Acesso em: 08 maio 2020.

QUEIROZ, Maria Isaura Pereira de. SCHLINGENSIEPEN, Ferdinand. Dietrich Bonhoeffer 19061945: Martyr, Thinker, Man of Resistance. London: T \& T Clark, 2010.

SELL, Wilhelm. Ser humano, ser para a outra pessoa: o significado da antropologia de Bonhoeffer para sua ética. Tese de doutorado (Teologia). São Leopoldo: Faculdades EST, 2019.

SOARES, Mário Lúcio Quintão. Teoria Geraldo do Estado. O substrato clássico e os novos paradigmas para o Direito Constitucional. Belo Horizonte: Del Rey, 2001.

TIETZ, Christiane. Theologian of Resistance. The Life and Thought of Dietrich Bonhoeffer. Minneapolis: Fortress Press, 2016.

WILLIAMS, Reggie. Bonhoeffer's Black Jesus. Harlem Renaissance Theology and an Ethic of Resistance. Waco: Baylor University Press, 2014. 